\title{
Optimum Annual Electricity Cost Through On-site Renewable Energy Generation and V2H Technology
}

\author{
Mohammad Sameti ${ }^{1}$, Mohammad Hossein Ahmadi ${ }^{{ }^{*}}$ and Michel Feidt ${ }^{2}$ \\ ${ }^{1}$ Department of Renewable Energies, Faculty of New Science and Technologies, University of \\ Tehran, Tehran, Iran \\ ${ }^{2}$ Laboratoired' Energétique et de Mécanique Théorique et Appliquée, ENSEM, 2, avenue de laForêt \\ de Haye 6060454518 Vandoeuvre, France
}

E-Mails: muh.sameti@ut.ac.ir; mohammadhosein.ahmadi@gmail.com; michel.feidt@univ-lorraine.fr

* Author to whom correspondence should be addressed; Tel.: +989122866205

Received: 15 July 2014 / Accepted: 31 October 2014 / Published: 3 November 2014

\begin{abstract}
The electrical energy stored in the batteries of plug-in electric vehicles can be utilized in intelligent house systems to proactively manage electricity energy consumption and costs. The vehicle-to-home ( $\mathrm{V} 2 \mathrm{H})$ technology has the potential to provide storage capacity to lower homes' energy costs and provide reliable backup systems in emergency periods. In this paper, the annual cost effects of integrating the electric plug-in vehicles into a hybrid solar PV/wind turbines driven residential district are investigated. These houses are located in a place where both real residential electricity consumption and meteorological data are available. The effects of number of turbines, PV panels and storage capacity on the annual cost reduction were also analyzed. The results showed that for a hybrid system comprising of ten $2 \mathrm{~kW}$ wind turbines and a $3 \mathrm{~kW}$ PV array, the $\mathrm{V} 2 \mathrm{H}$ technology can save more than $60 \%$ of the annual electricity cost.
\end{abstract}

Keywords: Annual Electricity Cost; wind turbines; energy costs; V2H technology

\section{Introduction}

The concept of simulation is the simultaneous solutions of the sets of equations (models) that describe the performance of the processes. The experimental behavior of the system cannot be 
described because of the unavailability of the inputs and outputs, dangerous testing condition, high cost of testing, noncompliance of the system time constants with the human dimensions and lack of clarity of the experimental behavior of the system due to the disturbance. On the other hand, Electricity production from modern renewable technologies in the residential sector is growing rapidly worldwide. Due to the high cost of building construction, any innovative idea should be already modeled to assure that the system is really beneficial.

An energy efficient building is simply defined as a building in which the thermal or electrical energy from renewable energy resources can supply the same highly reduced energy demands. Energy efficient building is a concept based on minimized energy demand and maximized harvest of local renewable energy resources. Such buildings' annual energy need can be supplied by one or more conventional or modern distribution energy systems such as electricity grid, district thermal system, gas pipe network, biomass and biofuels distribution networks [1]. The electrical components of an energy efficient building may be summarized as follows [2]: (i) smart meter which is a gateway between the building and the smart electrical grid, (ii) heat pump which reduces the energy required for interior heating, battery storage which serves as the backup energy during power failure or onpeak hours, solar photovoltaic and small wind turbine which serve as the supplementary power generation to meet the house energy demands, high efficiency lighting including modern CFL, LED, OLED which require less energy and home energy manager which controls and optimizes the energy flow in the house.

Figure (1) shows a schematic of the aforementioned system and the building boundary system which energy compares to flows and can flow in and out of the system [3]. It includes: (i) physical boundary which can encompass a single building or a group of buildings and determines whether renewable resources are on-site or off-site and (ii) balance boundary where it determines which energy uses (heating, cooling, ventilation, hot water, lighting, and appliances) are included in the balance. Here, we confine our study to balance boundary which encompasses small wind, photovoltaic array, battery and electricity grid. The model presented here exactly shows what a home energy manager does in Fig. (1) to optimize the cost of electricity purchased from the grid.

\subsection{Battery Storage}

In the building electrical boundary approach, battery storage is an essential component of the standby, emergency backup services and especially plug-in electric vehicle which is the concept known as vehicle-to-building (V2B) and vehicle-to-home (V2H) technologies. They are able to provide beneficial storage capacity to both vehicle and the building owners by lowering cost of the electric vehicles, reducing building's purchased energy and enabling reliable emergency power systems. The State of Charge (SOC) of a rechargeable battery (also, known as secondary battery) at any time is defined as

$$
S O C=\frac{C}{C_{\text {rated }}}
$$

where $C$ is the remaining capacity and $C_{\text {rated }}$ is the rated capacity both measured in Ampere-hours $(A h)$ which means delivering $C / k$ Amperes in $k$ hours [4].

\subsection{Photovoltaic \& Small Wind}

The efficient solar to electrical energy conversion using photovoltaic (PV) cells is one of the promising solutions for the global future energy demand. Solar cells are capable of converting the 
solar radiation into the electrical direct current (DC) through the so-called effect called photovoltaic. Photovoltaic modules or photovoltaic panels are made of the multiple interconnected solar cells. Owing to its low output power to meet the requirement of the house demands, photovoltaic arrays are usually utilized which are the linked collection of photovoltaic modules. To be applicable for household devices, the array output DC power should be converted to an alternative current (AC) via a device called inverter. Solar arrays electrical power are generally measured in watts $(W)$, kilowatts $(k W)$ and sometimes megawatts $(M W)$ [5]. As illustrated in Fig. (2), the array power generation varies from zero to its maximum value throughout the day.

A rotational flow driven machine which converts the kinetic energy from the moving air (wind) into the mechanical energy is called a wind turbine. Using a generator, the output mechanical energy is converted into the useful electricity. The relationship between the extracted mechanical power and the wind speed can be shown by a plot called a power curve. Figure (3) illustrates an idealized wind turbine power curve. The operating limits of a wind turbine is characterized by cut-in and cut-out speeds.

It can be seen from Fig. (3) that the power curve is divided into four distinct zones:

- Before cut-in wind speed consists of low wind speeds which there is not sufficient torque exerted by the wind on the turbine blades to make them rotate so no power can be extracted.

$\circ$ Between cut-in and rated wind speed is a transition region mainly concerned with keeping rotor torque and noise low and can be expressed as

$$
P=\frac{V-V_{\text {in }}}{V_{\text {out }}-V_{\text {in }}} \times P_{\text {rated }}
$$

where $P$ is the extracted power $(W), P_{\text {rated }}$ is the rated turbine power $(W), V$ is the wind speed $(\mathrm{m} /$ $s), V_{\text {in }}$ is the cut-in speed $(\mathrm{m} / \mathrm{s})$ and $V_{\text {out }}$ is the cut-out speed $(\mathrm{m} / \mathrm{s})$.

$\circ$ Between rated and cut-out wind speed which is relevant to higher wind speeds, the turbine design limit the output power to a maximum level (rated output power) and no further rise will happen in the extracted power.

- After cut-out speed (storm protection shut-down) there is a risk of damage to turbine structure and the control system stops the rotor.

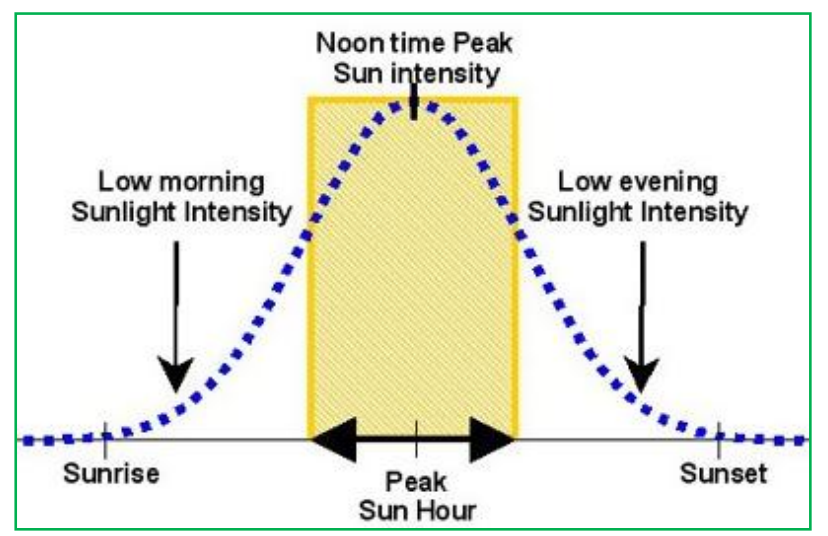

Fig. 2. Typical electricity PV generation profile [6] 


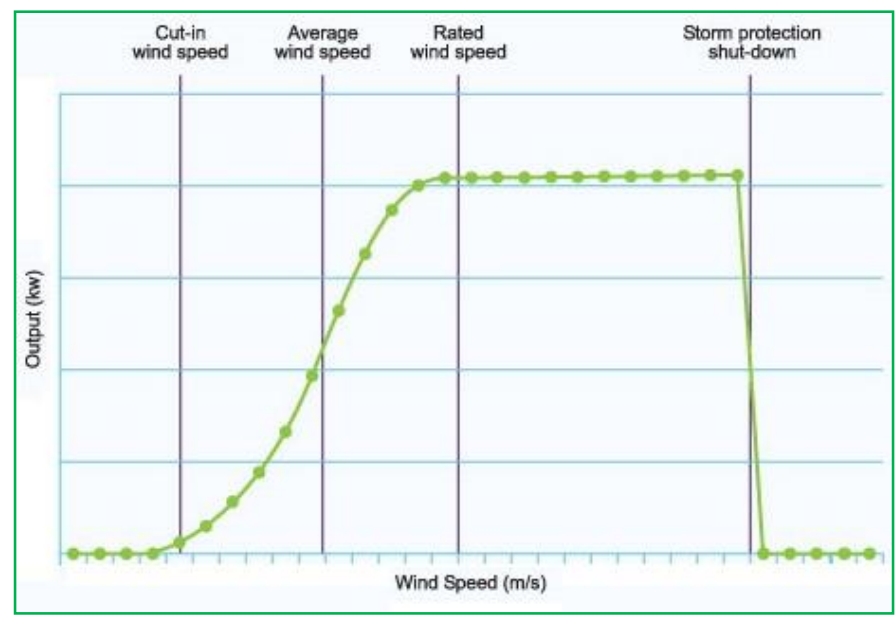

Fig. 3. Idealized wind turbine power curve [7]

\subsection{Smart Meter}

During the day, the smart meter has the option of charging various rates which are split into three separate periods according to demand for electricity: off-peak (low demand), mid-peak (moderate demand) and on-peak (high demand). The lowest prices are usually at night, on weekends and on holidays and are different throughout summertime and wintertime. Figure (4) shows a typical timeof-use price periods and is used in the model of the current study. Table (1) shows the assumed electricity rates in the current study.

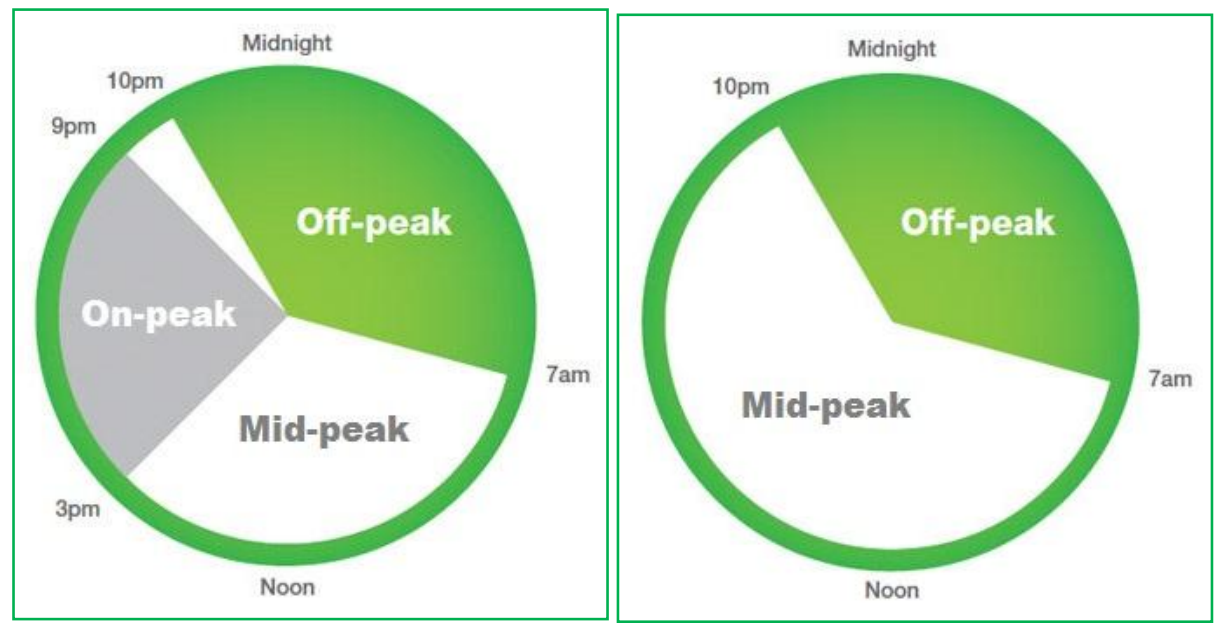

Fig. 4. Hourly separate periods of electricity demand for weekdays (up) and weekends (down) used in the model[8]

\section{Model Equation}

At each point of the time $t_{i}$ (here, we consider each point as an hour) where $0 \leq i \leq 24$, we can write the energy balance on the building system boundary as

$$
E_{w}\left(t_{i}\right)+E_{p v}\left(t_{i}\right)+E_{g}\left(t_{i}\right)=E_{b}\left(t_{i}\right)+E_{c}\left(t_{i}\right)
$$

where $E$ is the energy exchanged during 1 hour and the subscripts $w, p v, g, b$ and $c$ stand for wind turbine, photovoltaic panel, electrical grid, battery and the home energy demand, respectively. For 
the case of the battery, the exchanged energy is identical to its charging when $E_{c}<0$ and discharging when $E_{c}>0$, in other words

$$
E_{b}\left(t_{i}\right)=E_{b c}\left(t_{i}\right)-E_{b d}\left(t_{i}\right)
$$

where $c$ and $d$ denotes charging and discharging, respectively.

Taking the battery capacity into account, we can associate the state of the charge (SOC) and the exchange energy as following

$$
\operatorname{SOC}\left(t_{i}\right) C_{\text {rated }}=E_{b}\left(t_{i}\right)+\operatorname{SOC}\left(t_{i-1}\right) C_{\text {rated }}
$$

where the value of $S O C$ is always between its minimum and maximum levels.

$$
S O C_{\min } \leq S O C \leq S O C_{\max }
$$

The battery fault can be a reason for not assigning the values 0 and 1 to the minimum and maximum values of the $S O C$. As the second reason, the system owner probably like to ensure that there is always a charge remnant $S O C_{\text {min }} C_{\text {rated }}$ left in the battery. Eq. (2) is the simple case in which the battery efficiency considered to be $100 \%$ during charging and discharging. The more typical case can be written as (5).

$$
E_{b}\left(t_{i}\right)=E_{b c}\left(t_{i}\right) / \eta_{c}-\eta_{d} E_{b d}\left(t_{i}\right)
$$

where $\eta_{c}$ and $\eta_{d}$ are the battery efficiencies in charging and discharging modes, respectively.

The daily price of purchased electricity $B(c e n t)$ can be calculated using

$$
B=\sum_{i=1}^{24} B_{i}
$$

where $B_{i}$ (cent/hour) is the rate of electricity at the time $t_{i}$. Values of $B_{i}$ can be found in table (1). Assuming a constant daily trend throughout a month, the monthly electricity bill is calculated. The aim of the current simulation is to find the minimum value of $B$ denoted by $B_{\min }$.

Assumed value for the two first terms in Eq. (2) is depicted in Figs. (5) and (6). The PV array has a nominal power output of $3 \mathrm{~kW}$ and the small wind turbine specifications can be found in table (2).

In this study we considered a typical family which consumes electricity similar to what can be seen in Fig. (8). more information about load profile patterns can be found in ref. (14). The values of constants in Eqs. (5) and (6) in the model can be found in table (3).

Table 1. Rates of electricity in different periods (values of $B_{i}$ ) [9]

\begin{tabular}{cccc}
\hline Period & Off-peak & Mid-peak & On-peak \\
\hline $\begin{array}{c}\text { Price } \\
(\text { cent } / \mathrm{kWh})\end{array}$ & 7.2 & 10.9 & 12.9 \\
\hline
\end{tabular}

Table 2. Small wind turbine characteristics [10]

\begin{tabular}{cccc}
\hline \multicolumn{4}{c}{ Tanfon FD-2000 } \\
\hline$V_{\text {in }}(m / s)$ & $\begin{array}{c}V_{\text {out }}(\mathrm{m} / \\
\mathrm{s})\end{array}$ & $P_{\text {rated }}(k W)$ & Rotor Diameter $(m)$ \\
\hline 3.5 & 9.0 & 2.0 & 3.2 \\
\hline
\end{tabular}

Table 3. Battery specifications

\begin{tabular}{ccccc}
\hline $\boldsymbol{\eta}_{\boldsymbol{c}}$ & $\boldsymbol{\eta}_{\boldsymbol{d}}$ & $\boldsymbol{C}_{\text {rated }}$ & $\boldsymbol{S O C}_{\min }$ & $\boldsymbol{S O C}_{\max }$ \\
\hline 0.9 & 0.9 & $5 \mathrm{kWh}$ & 0 & 1.0 \\
\hline
\end{tabular}




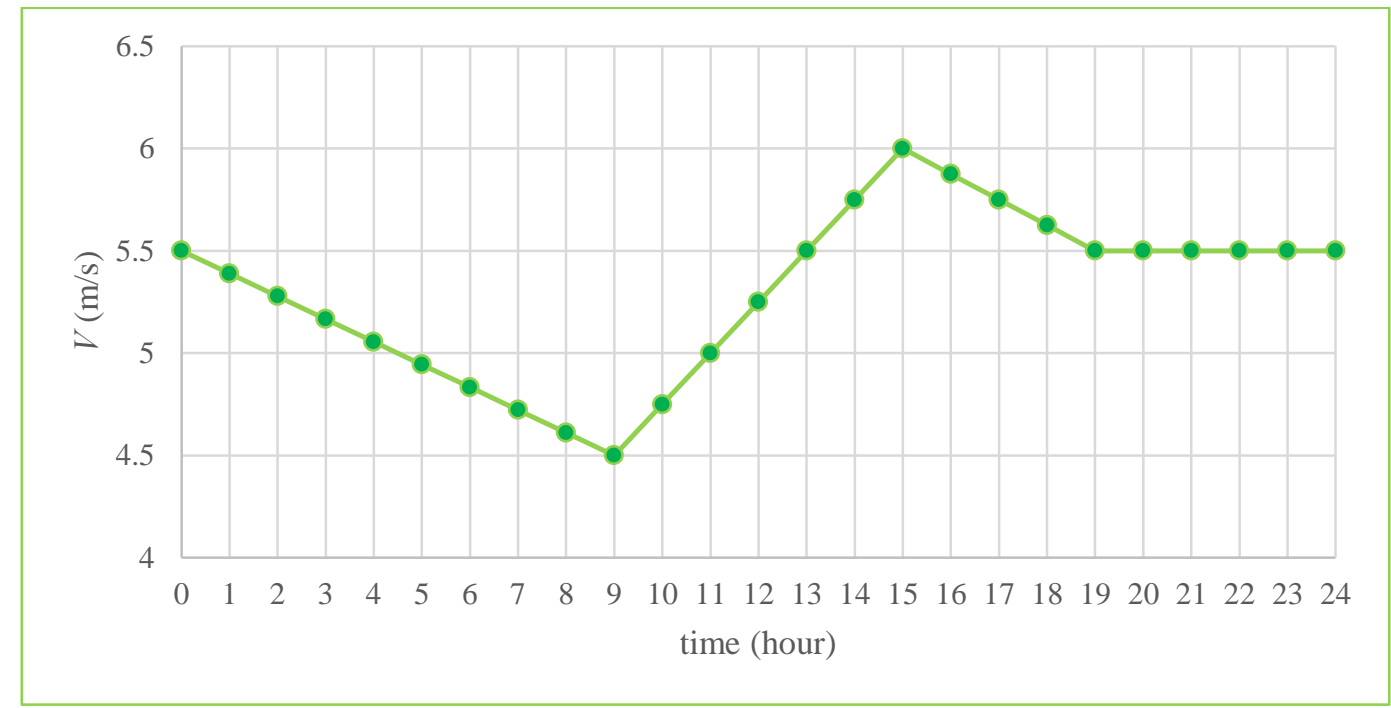

Fig. 5. Distribution of daily wind speed at turbine height used for the turbine power output [11] 


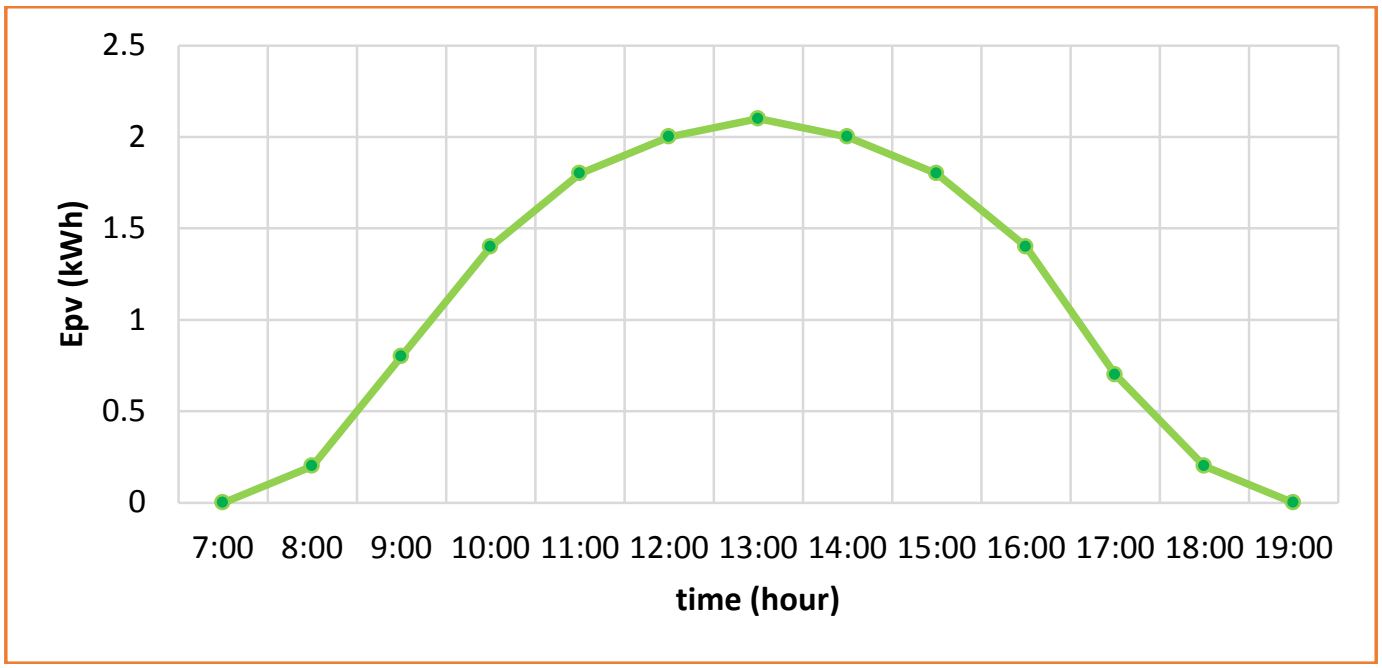

Fig. 6. Distribution of hourly photovoltaic energy generation [12]

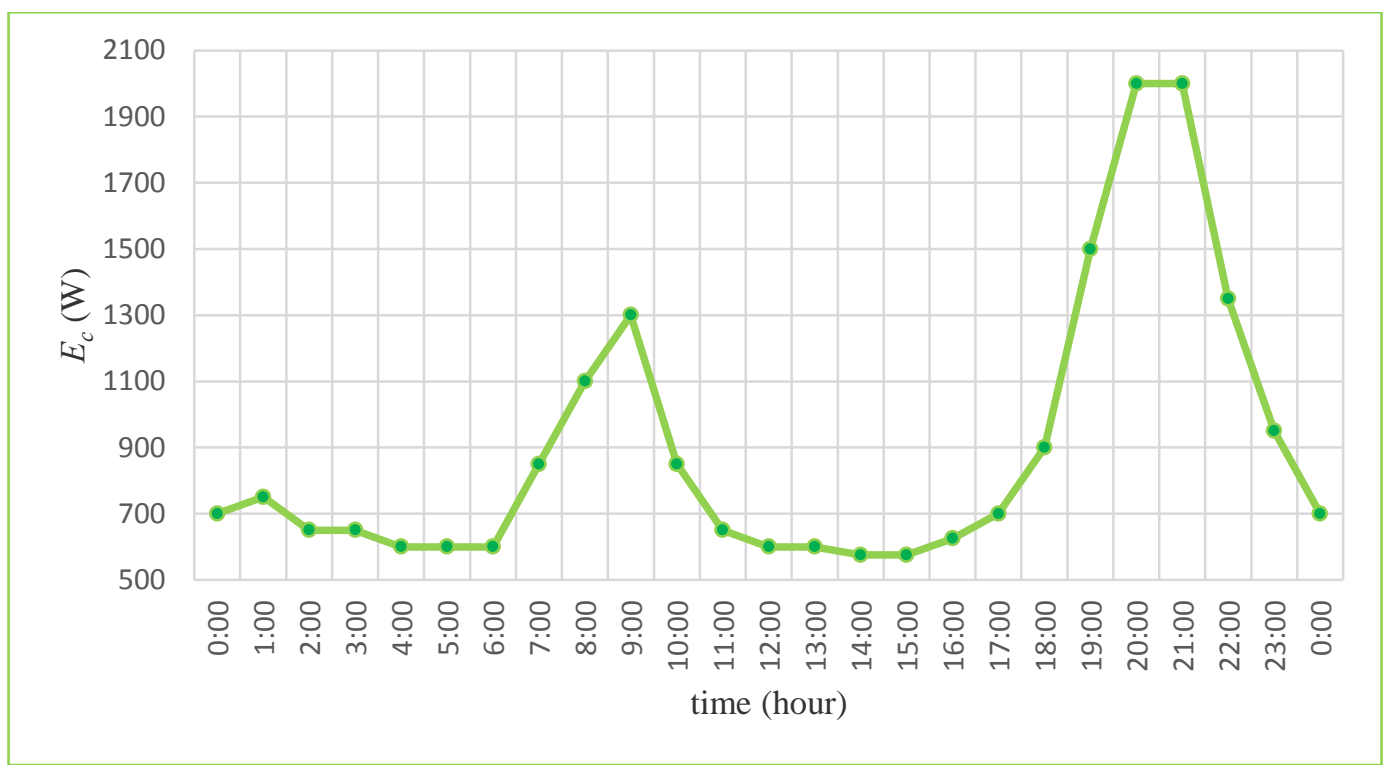

Fig. 7. Distribution of hourly energy consumption for a typical family [13]

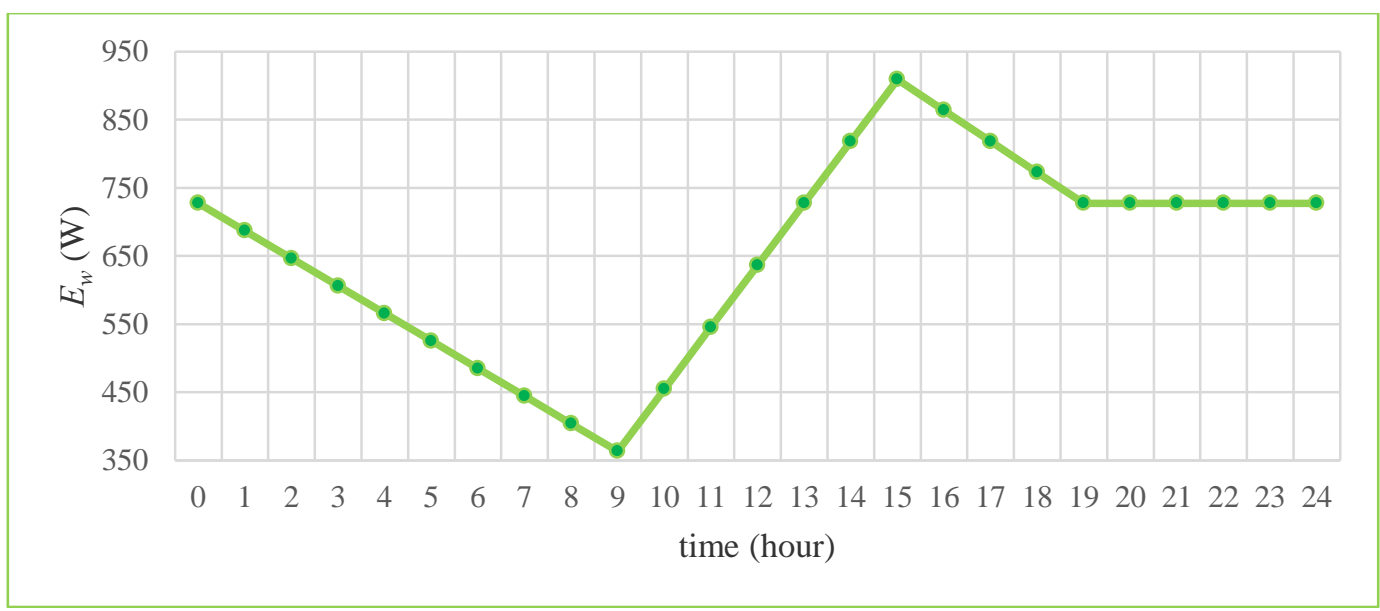

Fig. 8. Distribution of daily wind turbine power used in the model 


\section{General Algebraic Modelling System}

Equations (3) to (8) comprise a linear system of equations which can be solved using the General Algebraic Modeling System (GAMS) which is a high level modeling system [15] and is very similar to fourth generation programming systems. It is capable to globally solve linear programs as well as finding local optima of nonlinear programs. In this software, the programmer can build models which are expressed in simple and concise algebraic statements to find the optimum value of a predefined function. Here, the statements are very similar to the model equations (2) to (7) except for its initial condition is required by the software to solve the problem more efficiently. We put the value of $E_{b}\left(t_{i}\right)$ at $t_{i}=0$ to be $500 \mathrm{kWh}$ as can be seen in Fig. (11). Available input data for wind, PV and energy consumption along with the rate periods are imported to the system defining tables which pertains to each energy supplies/demands.

\section{Results and Discussions}

The hourly wind turbine output power $E_{w}\left(t_{i}\right)$ is calculated using Eq. (2) and Fig. (5). The output power is shown in Fig. (8) and is used in the model equations. Modeling the equation systems in GAMS, the monthly electricity bill $B$ is calculated in three cases:

- Case I: In presence of RET (renewable energy technology) with battery storage. In this case, there is a minimum value of $B$.

- Case II: In presence of RET without battery storage. Here, no minimum value of $B$ exist.

- Case III: In absence of RET.

It is assumed that the daily trend of energy consumption depicted in Fig. (7) continues for all the other days throughout a month. Figures (9) to (11) illustrates the simulation results. As table (4) shows, using all elements can save $96 \%$ in electricity cost while $22 \%$ of this reduction owes to the battery storage. The more the battery storage capacity was used the more the improvement is seen in the energy saving through shifting high amount of energy from off-peak to the on-peak hours.

Table 4. Simulation results for daily prices for different cases

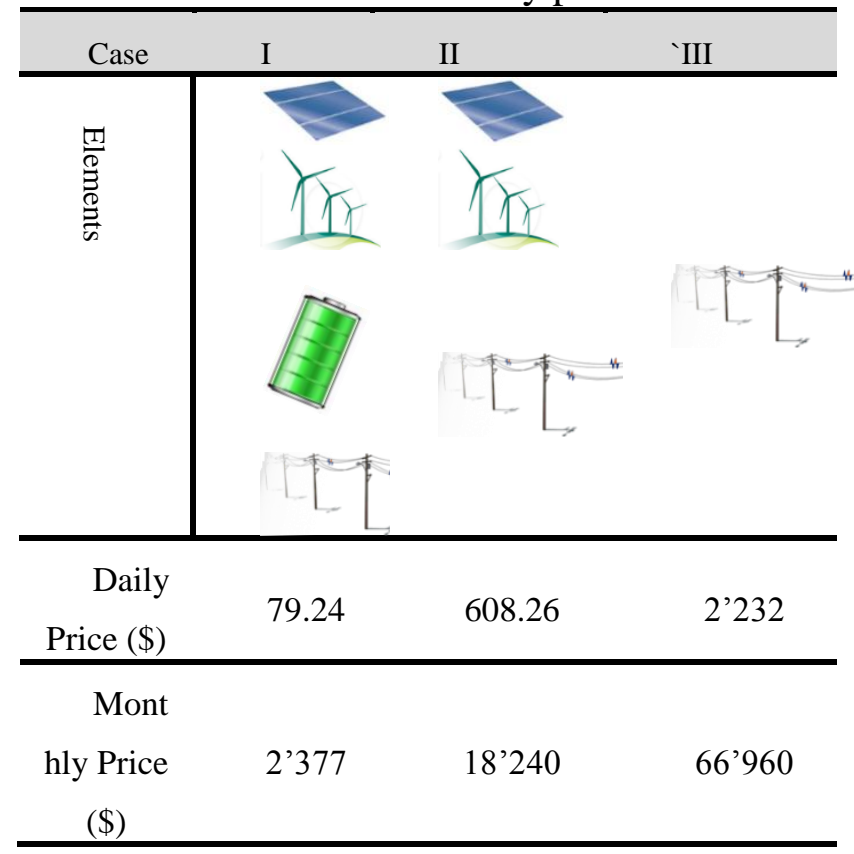




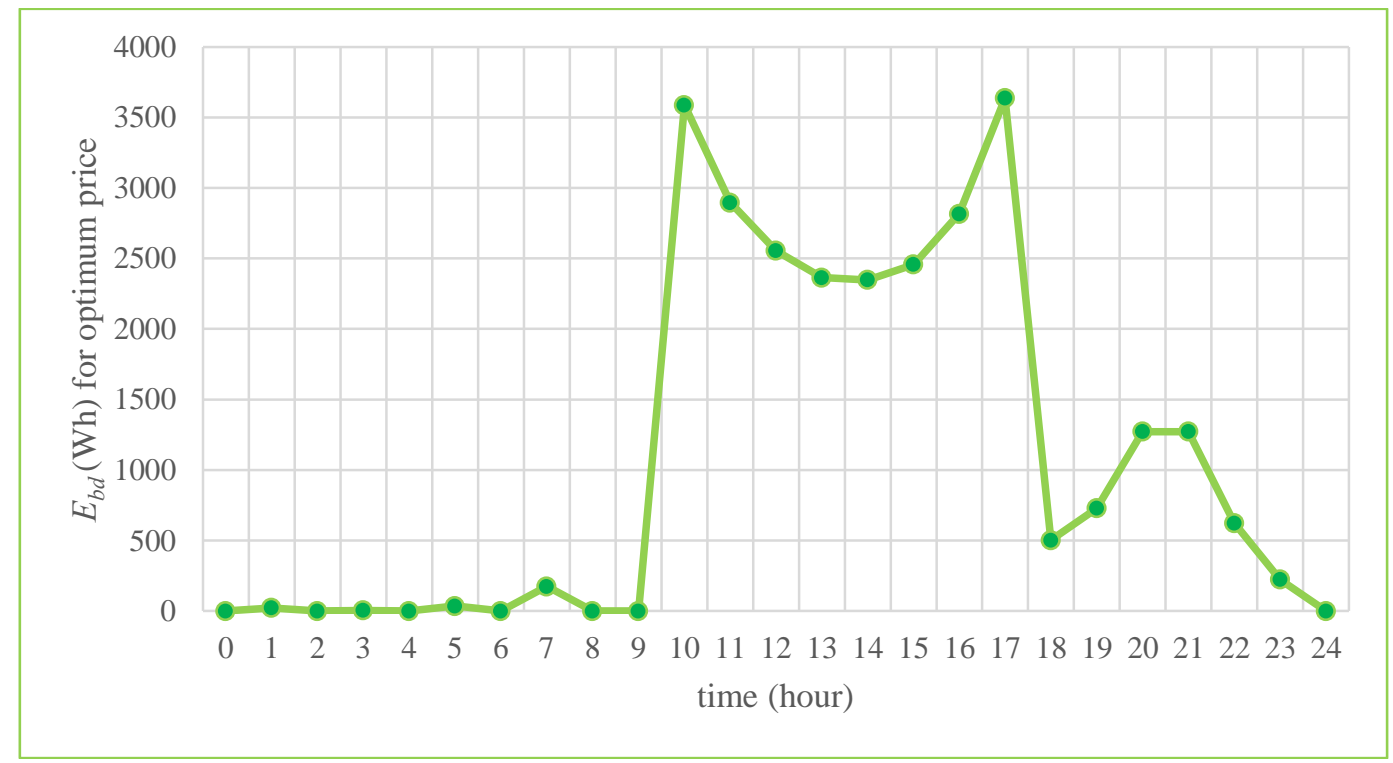

Fig. 9. Simulation results for hourly variations of power flow into the balance boundary of the building through battery storage in case I 


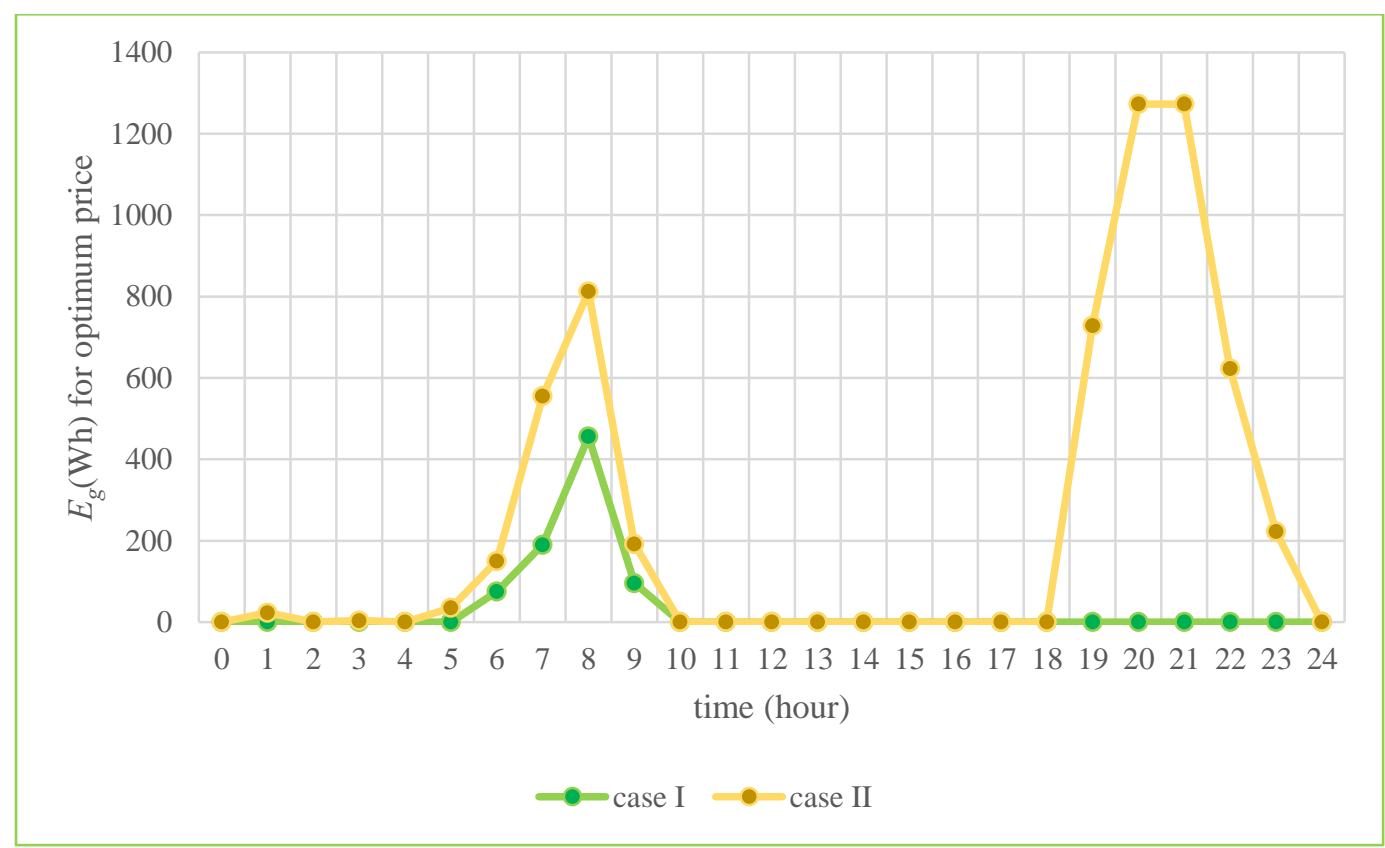

Fig. 10. Simulation results for hourly variations of power flow into the balance boundary of the building through electricity grid in cases I and II

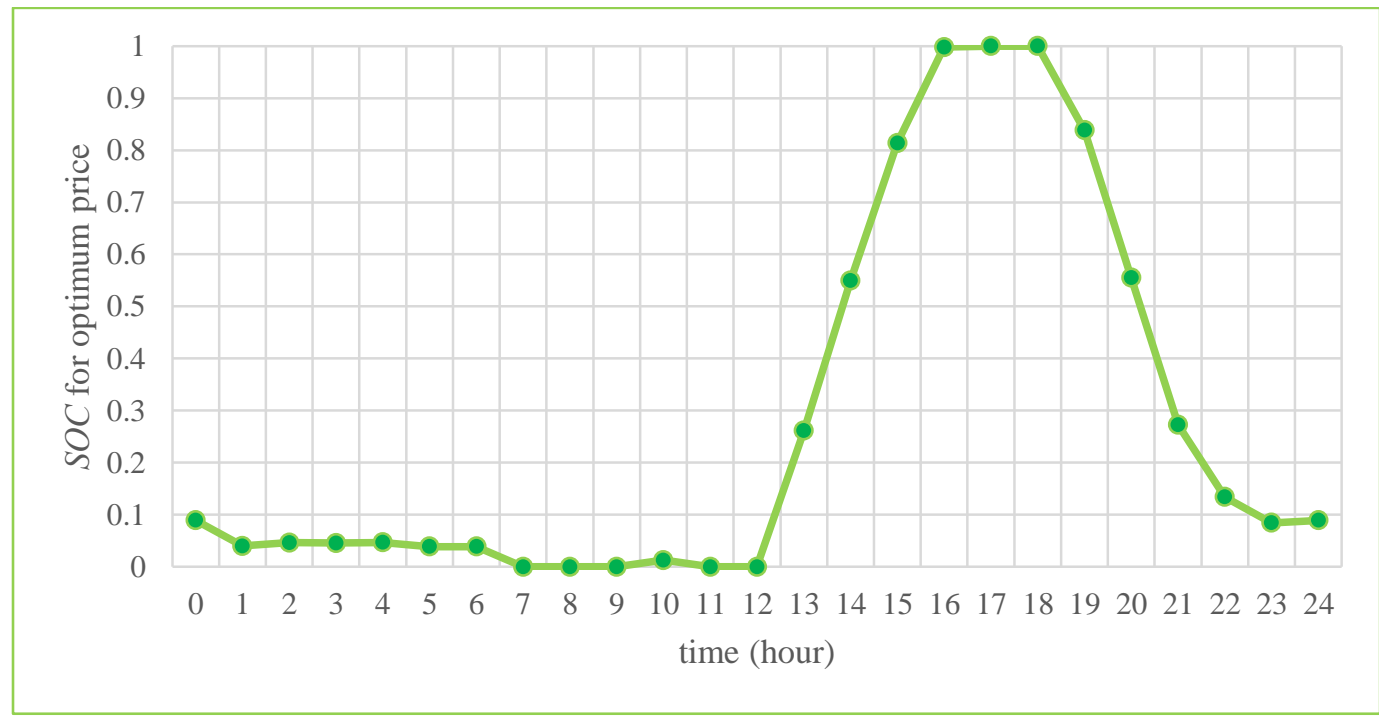

Fig. 11. Simulation results for hourly variations of battery state of charge (SOC) in case I

\section{Conclusion}

Energy efficient building is a modern concept which deals with providing the electrical or thermal energy from renewable energy resources to supply the buildings' annual energy demands. However Energy efficient buildings have different aspects, current research investigated them with electrical approach as the part of building balance boundary.

A simple model was developed to encompass the balance boundary aspect of a nearly zero energy building and the electricity cost was optimized to its minimum level using the GAMS software. Three different modes (RET with storage, RET without storage, conventional non-ZEB) were simulated to show how each element affect the monthly electricity bill. Electricity bill were calculated to be 2'377, 
18'240 and 66'960 dollars per month for each of the previous cases, respectively. Hourly variations of each energy flow were shown in different graphs. Besides free resources of renewable energies, the electrical energy storage which shifts the high-cost hours to the low-cost ones, is the main reason for this reduction.

\section{References and Notes}

1. www.zeb.aau.dk/digitalAssets/29/29578_nzeb-working-definition.pdf (accessed 2014/22/07)

2. Www.sustainableconstructionservices.com.au/products/future-products (accessed 2014/22/07)

3. Scognamiglio, A., \& Røstvik, H. N. (2012). Photovoltaics and zero energy buildings: a new opportunity and challenge for design. Progress in Photovoltaics: Research and Applications.

4. Patel, M. R. (2005). Wind and solar power systems: design, analysis, and operation. CRC press.

5. Tiwari, G. N., \& Dubey, S. (2010). Fundamentals of photovoltaic modules and their applications (No. 2). Royal Society of Chemistry.

6. solarexpert.com/solar-electric/performance-factors (accessed 2014/22/07)

7. www.pfr.co.uk/cloich/15/Wind-Power/119/Capacity-Factor (accessed 2013/22/07)

8. www.solarchoice.net.au/blog/victorian-government-applauded-for-energy-efficiencyproject (accessed 2013/22/07)

9. www.ontarioenergyboard.ca/OEB/Consumers/Electricity/Electricity+Prices (accessed 2013/22/07)

10. tanfon.en.alibaba.com/product/577125632-

209438303/3kw_to_5kw_wind_turbine_for_home_and_small_office_small_factory.html (accessed 2013/22/07)

11. www.engr.colostate.edu/ALP/ALP_91_Byers_East.html (accessed 2013/22/07)

12. http://blogs.scientificamerican.com/solar-at-home/2010/07/30/a-solar-detective-storyexplaining-how-power-output-varies-hour-by-hour (accessed 2013/22/07)

13. Arif, M. T., Oo, A. M., \& Ali, A. S. (2013). Estimation of Energy Storage and Its Feasibility Analysis.

14. The impact of commercial and residential sectors' EEIs on electricity demand. EMET Consultants Pty Limited. 2004. Online resource: www.ret.gov.au/Documents/mce/energyeff/nfee/_documents/ consreport_07_.pdf

15. www.gams.com (accessed 2014/22/07)

(C) 2014 by the authors; licensee MDPI, Basel, Switzerland. This article is an open access article distributed under the terms and conditions of the Creative Commons Attribution license. 